\title{
A CASE REPORT OF A FAMILY SUFFERING FROM AXENFELD RIEGER'S SYNDROME
}

\author{
Awargaonkar A. V1, Une V. L², Khaire B. S3
}

\section{HOW TO CITE THIS ARTICLE:}

Awargaonkar A. V, Une V. L, Khaire B. S. "A Case Report of a Family Suffering from Axenfeld Rieger's Syndrome". Journal of Evolution of Medical and Dental Sciences 2014; Vol. 3, Issue 29, July 21; Page: 8005-8011, DOI: $10.14260 /$ jemds/2014/3003

\begin{abstract}
Axenfeld - Rieger syndrome is an autosomal dominant disorder affecting the anterior segment of the eye. The incidence of glaucoma is high and it is the main cause of blindness in Axenfeld - Rieger syndrome. Three chromosomal loci have been demonstrated to link to Axenfeld Rieger syndrome and related phenotypes. These loci are on chromosomes 4q25, 6p25, 13q14 and very recently chromosome 11 . The genes at chromosomes $4 \mathrm{q} 25$ and $6 \mathrm{p} 25$ have been identified as PITX2 and FOXC1. These genes specify migration and differentiation of mesenchymal progenital cells of neural crest origin into distinct anterior segment tissues. We present to you a case which came to our out-patient department with complaints of diminution of vision which on further investigation leads us to a family suffering from this disease from five generations. All the patients gave history of having diminution of vision since birth and demonstrated common picture of photophobia, iris adhesion, iris holes, prominent Schwalbe's line, increased intraocular tension and glaucomatous changes on the disc on fundus examination. The case report emphasizes the grave importance of long-term follow and counseling, as the symptoms may only be a part manifestation of a potentially blinding syndrome.
\end{abstract}

KEYWORDS: anterior segment dysgenesis, corectopia, iris holes, posterior embryotoxon, iris stromal hypoplasia.

INTRODUCTION: Anterior segment dysgenesis is a failure of normal development of the anterior segment of the eye. Axenfeld-Rieger syndrome (ARS) (MIM 180500) is an autosomal dominant disorder with variable gene expression which affects the development of the teeth, eyes and abdominal region. Because of the anterior segment anomalies there is an increased risk of glaucoma.[1,2]

Axenfeld anomaly also called posterior embryotoxon, is a congenital anomaly in which Schwalbe's line is anteriorly displaced and is associated with iris bands that extend to the cornea. [3] Rieger anomaly is the term used to describe iris and pupillary abnormalities i.e. iris holes and corectopia in combination with the findings of the Axenfeld anomaly. [3] Rieger anomaly is associated with the late onset of glaucoma.

If the Rieger anomaly is associated with dental and skeletal abnormalities, the condition is called Rieger Syndrome.[3] Recently Axenfeld's anomaly and Rieger's Anomaly/Syndrome have been re-classified as Axenfeld-Rieger syndrome as the two conditions have many overlapping features.[3] We report an individual who came with the complaints of diminution of vision who later revealed that his entire family is suffering from Axenfeld Rieger syndrome.

CASE REPORT: A 30years old adult male came to our outpatient department with the complaints of diminution of vision of both eyes. On preliminary examination, right eye showed both ciliary and 
conjunctival congestion, iris adhesions, iris holes, prominent Schwalbe's line and a grayish white reflex in pupillary aperture his vision was 20/200.

Left eye showed both ciliary and conjunctival congestion, iris holes, iris adhesions, prominent Schwalbe's line and a white reflex in pupillary aperture his vision in left eye was finger counting close to face; in addition he had ciliary staphyloma and a filtering bleb at $12^{\circ}$ clock. He was investigated for cataract and underwent Left eye temporal small incision cataract surgery with posterior chamber intraocular lens implantation although placement of intraocular lens was difficult due to iris holes but was uneventful. His postoperative BCVA was 20/200, fundus examination showed mild disc pallor with Cup to Disc ratio of 0.7 to 0.8 NRM was irregular and there was nasal shifting of vessels. Cardiac anomalies and sensorineural deafness was not seen.

During the course of his treatment the patient gave history of similar complaints in his family members. He also informed that his family has been suffering from diminution of vision since five generations. He was advised to bring his family members for examination.

His great grandfather and grandfather were deceased. His father, sister, brother and their children attended the out-patient department along with his cousin brothers, sisters and their children.

Most of them examined showed a common picture of photophobia, iris adhesion, iris holes, prominent Schwalbe's line, increased intraocular tension and glaucomatous changes on the disc on fundus examination. None of the patients demonstrated cardiac anomalies or sensorineural deafness. These findings were found to be present in three generations and the history given by the patient and his relatives suggested that both, their grandfather and great Grandfather suffered from similar complaints.

Based on the history and clinical findings a diagnosis of Axenfeld-Rieger syndrome was made. Subsequently the patient's brother, sister and son underwent trabeculectomy for both eyes. The intraocular tension of his nephew was well controlled with anti-glaucoma drugs and all of them were advised regular follow up.

Rest of the family members refused surgical treatment hence were advised medical treatment and regular follow up. Cytogenetic and molecular studies could not be done due to patient refusal

DISCUSSION: Axenfeld-Rieger syndrome (ARS) (MIM 180500) is an autosomal dominant disorder with variable gene expression.

In our report this variable expression of the gene is amply demonstrated, the family tree also clearly indicates that healthy individuals who married a healthy partner had a normal progeny. In two instances in spite of one of the two partners being affected with Axenfeld-Rieger syndrome still they had normal children.

The current and most widely held theory for development of Axenfeld - Rieger Syndrome suggests a developmental arrest of specific anterior segment tissues derived from neural crest cells, which apparently occurs late in gestation. ${ }^{[3]}$ The result is the retention of a primordial endothelial cell layer on portions of the iris and angle structures. Contraction of these endothelial "membranes" leads to the associated abnormalities in form and function of the anterior segment structures.[4]

Main features of Axenfeld - Rieger Syndrome are bilateral developmental ocular abnormalities which may be asymmetrical, umbilical cord anomalies, dental abnormalities include a reduction in crown size (microdontia), a decreased but evenly spaced number of teeth (hypodontia), 
and a focal absence of teeth, (oligodontia or anodontia). ${ }^{[5]}$ Facial anomalies include maxillary hypoplasia with flattening of the midface and a receding upper lip and prominent lower lip, especially in association with dental hypoplasia.[6]

During our examination we did not find any umbilical, dental or facial anomalies. We also did not find any patient who demonstrated cardiac anomalies or sensorineural deafness.

Ocular manifestations of Axenfeld - Rieger syndrome are typically bilateral and congenital. The structures most commonly involved are the peripheral cornea, anterior chamber angle and iris. These include iris stromal hypoplasia, ectropion uveae, corectopia, full-thickness iris defects, severe iris atrophy, prominent, anteriorly displaced Schwalbe's line and extensive peripheral anterior synechiae. ${ }^{[3]}$

The atrophy and iris hole formation typically occur in the quadrant away from the direction of the corectopia. Glaucoma develops in nearly $50 \%$ of cases, usually during early childhood or early adulthood, due to an associated angle anomaly or secondary synechial angle closure. ${ }^{[3]}$ Schlemm's canal may be small or absent, development of trabecular meshwork is aberrant and extracellular matrix is altered.[2]

All our patients demonstrated ocular findings in the form of, iris adhesion, iris holes, prominent Schwalbe's line, increased intraocular tension and glaucomatous changes on the disc on fundus examination. Some of them however had leucomatous corneal opacities, ciliary staphyloma and calcific band keratopathy.

Several different gene mutations, encoding for transcriptional regulators have been described. Three chromosomal loci have been demonstrated to link to Axenfeld Rieger syndrome and related phenotypes. These loci are on chromosomes $4 \mathrm{q} 25,6 \mathrm{p} 25,13 \mathrm{q} 14$ and very recently chromosome 11.[7-10] The genes at chromosomes 4q25 and 6p25 have been identified as PITX2 and FOXC1. ${ }^{[8]}$ About $40 \%$ of Axenfeld - Rieger sufferers display mutations in one of the genes known as PAX6, PITX2 and FOXC1. These genes specify migration and differentiation of mesenchymal progenital cells of neural crest origin into distinct anterior segment tissues.

In our case cytogenetic and molecular studies could not be done due to patient refusal and incurring expenses.

CONCLUSION: The ocular and systemic features of Axenfeld-Rieger syndrome are well described in literature. The condition can lead to gradual and irreversible visual loss due to associated glaucoma and needs specialist care and careful monitoring. The primary area of concern regarding the management of ocular defects in a patient with the Axenfeld -Rieger syndrome is early detection and control of the associated glaucoma.

Intraocular pressure elevation most often develops between childhood and early adulthood, but it may appear in infancy or, in rare cases, not until late adulthood.[3] Patients with the Axenfeld Rieger syndrome must be followed to detect glaucoma throughout their lives. Our case emphasizes the grave importance of long-term follow and counseling, as the symptoms may only be a part manifestation of a potentially blinding syndrome.

\section{REFERENCES:}

1. Sowden JC. Molecular and developmental mechanisms of anterior segment dysgenesis. Eye 2007; 21:1310-18. 
2. Gould DB, John SW. Anterior segment dysgenesis and the developmental glaucoma's are complex traits. Hum Mol Genet 2002; 11:1185-93.

3. Shields MB. Axenfeld-Rieger syndrome: A theory of mechanism and distinctions from the iridocorneal endothelial syndrome. Trans Am Ophthalmol Soc 1983; 81:736-84.

4. Reneker LW, Silversides DW, Xu L, Overbeek PA. Formation of corneal endothelium is essential for anterior segment development - a transgenic mouse model of anterior segment dysgenesis. Development 2000; 127:533-42.

5. Wesley RK, Baker JD, Golnick AL. Rieger's syndrome: (oligodontia and primary mesodermal dysgenesis of the iris) clinical features and report of an isolated case. J Pediatr Ophthalmol Strabismus 1978; 15: 67-70.

6. Piper HF, Schwinger E, von Domarus H. Dysplasia of the corneal limbus, the mesodermal iris layer and the jaw skeleton in a family. Klin Monbl Augenheilkd 1985; 186: 287-93.

7. Amendt BA, Semina EV, Alward WL. Rieger syndrome: a clinical, molecular and biochemical analysis. Cell Mol Life Sci 2000; 57:1652-66.

8. Alward WL. Axenfeld-Rieger syndrome in the age of molecular genetics. Am J Ophthalmol 2000; 130:107-15.

9. Semina EV, Reiter R, Leysens NJ, Alward WL, Small KW, Datson NA, et al. Cloning and characterization of a novel bicoid-related homeobox transcription factor gene, RIEG, involved in Rieger syndrome. Nat Genet 1996; 14: 392-99.

10. Riise R, Storhaug K, Brøndum-Nielsen K. Rieger syndrome is associated with PAX6 deletion. Acta Ophthalmol Scand 2001; 79:201-3.

Figure 1: Family tree of the affected family.

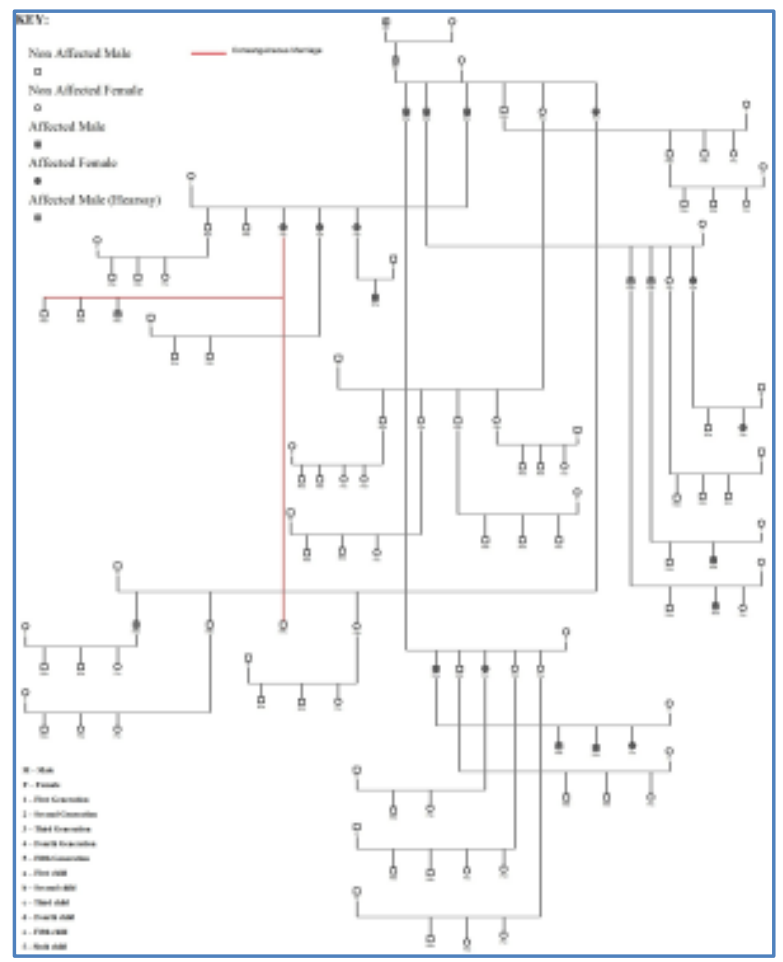

Figure 1 


\section{CASE REPORT}

Figure 2: 5th generation family member showing corectopia \& prominent schwalbe's line.

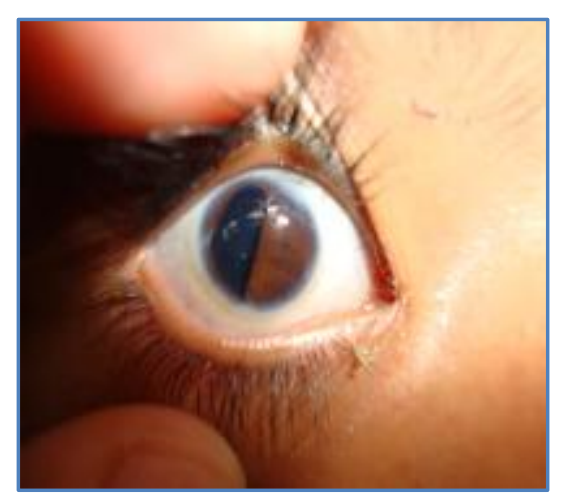

Figure 2

Figure 3: 4th generation family member showing corectopia, prominent schwalbe's line, ciliary staphyloma \& corneal edema.

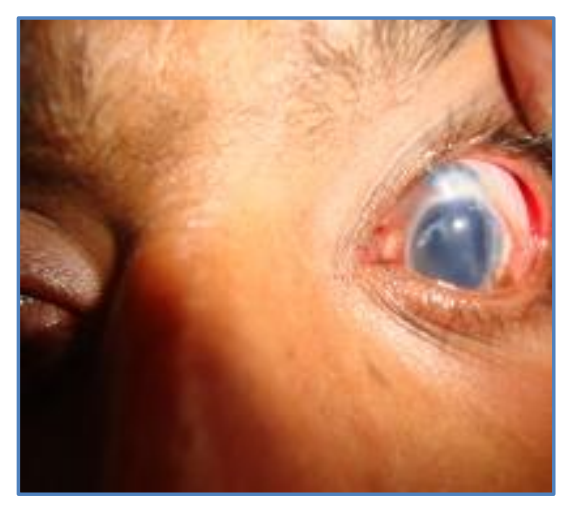

\section{Figure 3}

Figure 4: 4th generation family member showing iris holes corectopia and extensive corneal opacities.

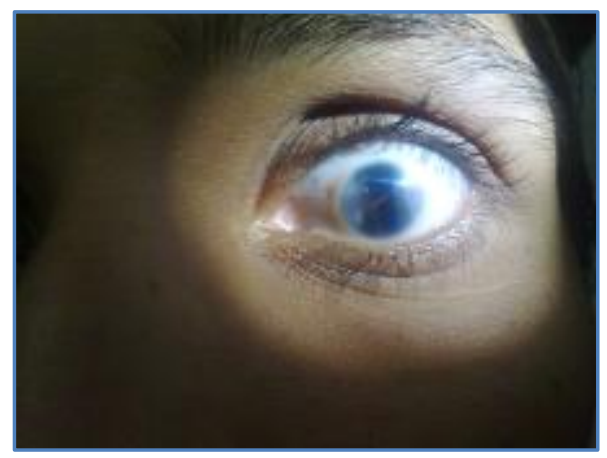

\section{Figure 4}




\section{CASE REPORT}

Figure 5: One of the 4th generation family member (brother of the patient who reported to OPD) who underwent cataract extraction with PCIOL, showing iris holes and a prominent schwalbe's line.

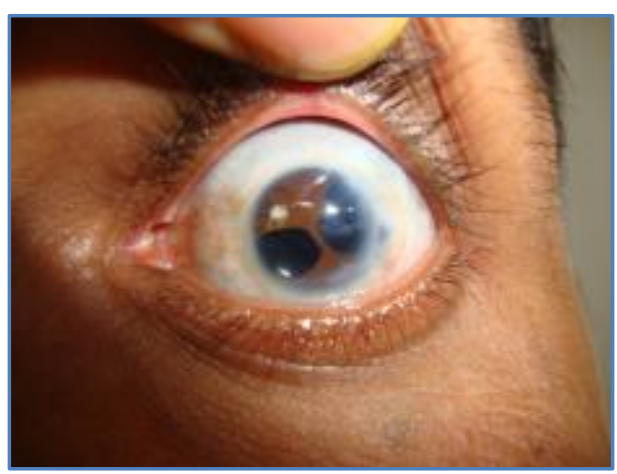

Figure 5

Figure 6: 5th generation family member with corneal edema in both eyes secondary to extensive iris adhesions.

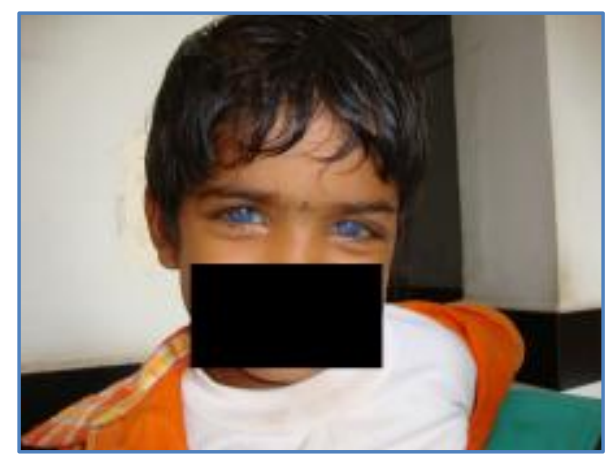

Figure 6

Figure 7: Slit Lamp Photograph showing early Cataract, Prominent iris holes, Corectopia, Prominent and anteriorly placed schwalbe's line.

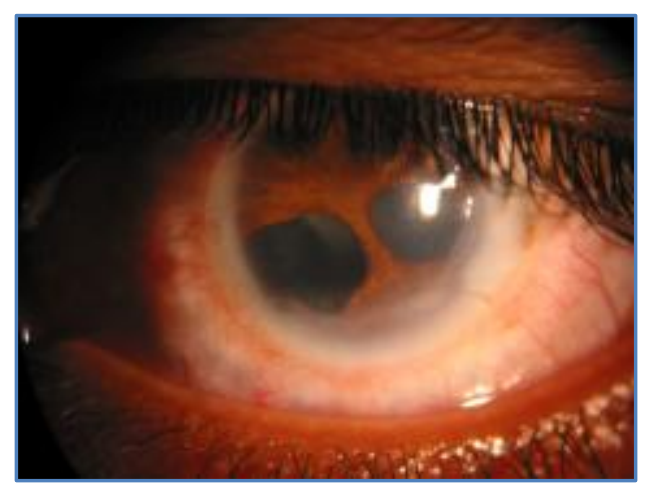

\section{Figure 7}




\section{CASE REPORT}

Figure 8: Slit Lamp Photograph showing advanced Cataract, multiple iris holes, Corectopia, Prominent and anteriorly placed schwalbe's line.

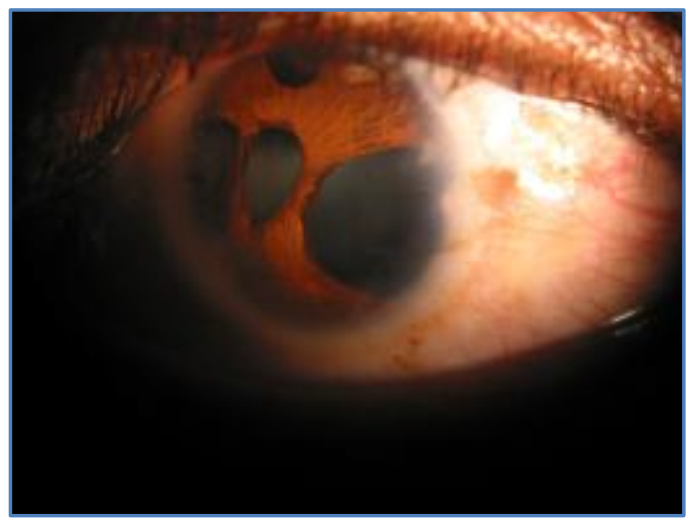

Figure 8

\section{AUTHORS:}

1. Awargaonkar A. V.

2. Une V. L.

3. Khaire B.S.

\section{PARTICULARS OF CONTRIBUTORS:}

1. Assistant Professor, Department of Ophthalmology, Government Medical College, Aurangabad.

2. Associate Professor, Department of Ophthalmology, Government Medical College, Aurangabad.

3. Professor, Department of Ophthalmology, Government Medical College, Aurangabad.

\section{NAME ADDRESS EMAIL ID OF THE} CORRESPONDING AUTHOR:

Dr. Awargaonkar Amarnath Vijaykumar, C/o Hotel Panchavati, Station Road, Padampura, Aurangabad-431001, Maharashtra.

Email: amar.awargaonkar@gmail.com

Date of Submission: 08/07/2014. Date of Peer Review: 09/07/2014. Date of Acceptance: 14/07/2014. Date of Publishing: 16/07/2014. 